\title{
Enhanced Mechanical Properties of Pure Zirconium via Friction Stir Processing
}

\author{
Wen Wang ${ }^{1,2} \cdot$ Peng Han ${ }^{1,2} \cdot$ Jie Yuan ${ }^{1,2} \cdot$ Pai Peng ${ }^{1,2} \cdot$ Qiang Liu $^{1,2} \cdot$ Fei Qiang $^{1,2} \cdot$ Ke Qiao $^{1,2} \cdot$ Kuai-She Wang $^{1,2}$
}

Received: 9 April 2019 / Revised: 4 June 2019 / Published online: 19 October 2019

(C) The Chinese Society for Metals (CSM) and Springer-Verlag GmbH Germany, part of Springer Nature 2019

\begin{abstract}
Friction stir processing (FSP), as a new kind of severe plastic deformation technique, can refine and homogenize the microstructure of metallic material. In this study, the effect of FSP on the microstructure and mechanical properties of pure $\mathrm{Zr}$ was investigated using electron backscatter diffraction analysis, microhardness and room-temperature tensile testing. The fine-grained (FG) structure with an average grain size of $\sim 5.3 \mu \mathrm{m}$ was obtained in the processed zone, where the average microhardness was $\sim 198 \mathrm{HV}, 1.6$ times higher than that of base metal. Furthermore, tensile property of FG pure $\mathrm{Zr}$ exhibited obvious anisotropy owing to strong texture. Both grain size and texture had a significant effect on strength and ductility of FG pure Zr. High yield strength (248 MPa) and ultimate tensile strength (483 MPa), as well as good uniform elongation (10\%) were achieved, which demonstrated that FSP was an effective method to fabricate bulk FG pure $\mathrm{Zr}$ with high strength and good ductility.
\end{abstract}

Keywords Friction stir processing $\cdot$ Pure zirconium $\cdot$ Grain size $\cdot$ Texture $\cdot$ Mechanical property

\section{Introduction}

In order to obtain fine-grained (FG) materials with high strength and reasonable ductility, a great attention has been focused on the application of severe plastic deformation (SPD) technique. It is well known that SPD techniques, such as equal channel angular pressing (ECAP) [1, 2], high-pressure torsion (HPT) [3], accumulative roll bonding (ARB) [4], and several variants of these, can fabricate FG and even ultrafine-grained (UFG) materials with excellent strength. However, FG and UFG materials fabricated by these traditional SPD techniques usually have lower strain hardening capability and plasticity than corresponding coarse-grained (CG) materials.

Available online at http://link.springer.com/journal/40195

Wen Wang

wangwen2016@126.com

$\triangle$ Kuai-She Wang

wangkuaishe888@126.com

1 School of Metallurgical Engineering, Xi' an University of Architecture and Technology, Xi' an 710055, China

2 National and Local Joint Engineering Research Center for Functional Materials Processing, Xi' an 710055, China
Friction stir processing (FSP), a variation of friction stir welding (FSW) [5], is a new SPD technique during which microstructural refinement $[6,7]$, homogenization [8] and densification [9] occur simultaneously. It is worth mentioning, FSP can fabricate bulk FG and UFG materials with a high ratio of high-angle grain boundaries and low dislocation densities [10-12]. Thus, it is viable to improve the strength and keep a good ductility of FG and UFG materials $[13,14]$.

Zirconium (Zr) with a hexagonal close-packed (hcp) structure was widely used in the nuclear industry, aviation, and surgical implant owing to its excellent resistance to corrosion, irradiation, and good biocompatibility [15]. Several previous studies have demonstrated that FSP can enhance both the strength and ductility of face-centered cubic (fcc) metals ( $\mathrm{Al}, \mathrm{Cu}$, etc.) [16-18]. Nevertheless, there is little to know for FSP $\mathrm{Zr}$ to enhance its strength and ductility simultaneously [19-22]. Only a few reports were aimed at the microstructure and mechanical properties of FSW Zr alloy joint.

Sato et al. [19] successfully used FSW to weld Zircaloy-4 alloy. A defect-free weld with fine equiaxed grains in the processed zone (PZ) was obtained, which caused an increase in hardness. Moreover, Li et al. [23] indicated that a 3-mmthick $\mathrm{Zr}$-Ti alloy plate was successfully joined using FSW. 
The microhardness of the joint exhibited an integral decrement and uniform distribution. The ultimate tensile strength and elongation were equal to the base metal (BM). Tensile fracture occurred at the heat-affected zone. The fracture surface exhibited a mixing feature with quasi-cleavage facets and small dimples. In addition, $\mathrm{Xu}$ et al. [24] reported the influence of liquid nitrogen cooling on the microstructure and mechanical properties of FSW joint of $\mathrm{Zr}-4$ alloy. The PZ has a UFG structure with high dislocation densities and abundant twin boundaries. Grain subdivision and discontinuously dynamic recrystallization contributed most to grain refinement. A good match of strength and uniform elongation was achieved by liquid nitrogen cooling.

In this study, we chose $\mathrm{Zr}$ as a model metal, and succeeded in fabricating the FG structure via FSP, yielding a simultaneous enhancement of strength and ductility. The microstructure and anisotropic mechanical properties of FSP $\mathrm{Zr}$ were investigated in detail.

\section{Experimental}

A cold-rolled and annealed commercial pure $\mathrm{Zr}$ (Zr702) plate with the dimension of $100 \mathrm{~mm} \times 60 \mathrm{~mm} \times 3 \mathrm{~mm}$ was used in this study. FSP was conducted with an X5032 vertical milling machine at a rotation rate of $300 \mathrm{rpm}$ and a traverse speed of $118 \mathrm{~mm} / \mathrm{min}$. A WC stir tool consisted of a flat shoulder with a diameter of $14 \mathrm{~mm}$ and a 1.6-mm-long pin. The pin diameter was tapered from $5 \mathrm{~mm}$ at the shoulder to $3.5 \mathrm{~mm}$ at the pin tip. The reduction in thickness of the shoulder was $0.2 \mathrm{~mm}$ with a tilt angle of $2^{\circ}$. In order to avoid oxidation, argon shield was adopted during FSP. The processing direction (PD) was parallel to rolling direction (RD) of $\mathrm{Zr}$ plate.

The microstructure of FSP specimen was observed by an optical microscope (OM, Leica DM2500 M) and electron backscatter diffraction (EBSD, Zeiss Merlin Compact) technique, respectively. Both OM and EBSD specimens were vertically cut to the $\mathrm{PD}$, as shown in Fig. 1a. OM specimens were polished and etched using an etching reagent $(20 \mathrm{~mL}$ hydrofluoric acid, $90 \mathrm{~mL}$ nitric acid, and $90 \mathrm{~mL}$ distilled water). EBSD specimens were prepared by electrochemical polishing with a $10 \%$ perchloric acid-ethanol solution at $-30{ }^{\circ} \mathrm{C}$. Pole figures (PFs), inverse pole figures (IPFs), misorientation angle distribution, and grain size distribution were acquired via EBSD testing. In the IPFs, low-angle boundaries (LABs) and high-angle boundaries (HABs) were depicted as red and black lines, respectively. A $15^{\circ}$ criterion was used to define HABs versus LABs. In order to eliminate spurious boundaries induced by orientation noise, a lower limit boundary misorientation $2^{\circ}$ was cutoff.

Following FSP, microhardness testing was performed on the cross section perpendicular to the PD using a 401
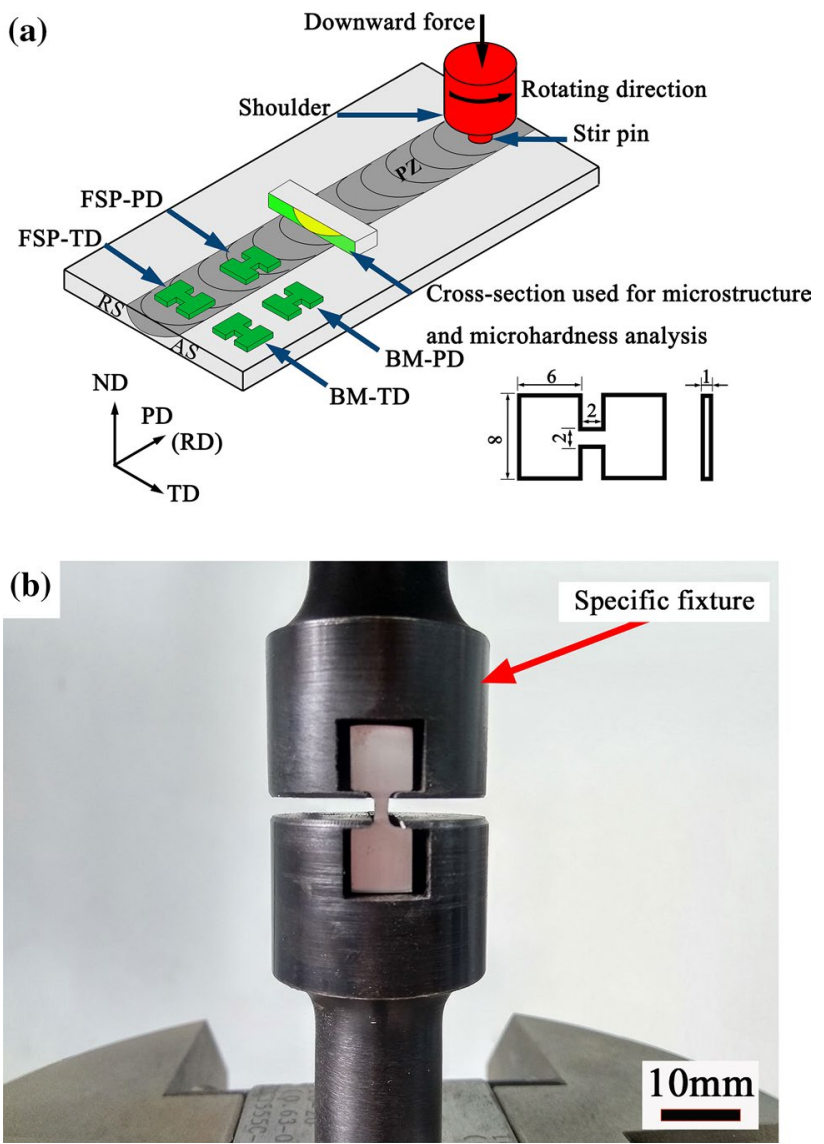

Fig. 1 a Illustration of FSP and sampling position, b specific fixture used for tensile testing. $A S$ Advancing side, $R S$ retreating side, $P D$ processing direction, $T D$ transverse direction, $N D$ normal direction, $R D$ rolling direction

MVD microhardness tester with a load of $200 \mathrm{~g}$ and dwell time of $10 \mathrm{~s}$, with a space between adjacent indentations of $0.5 \mathrm{~mm}$. The microhardness matrix map was plotted using Origin software. Tensile testing was conducted on an Instron 8801 testing machine at room temperature, with an initial strain rate of $1 \times 10^{-3} \mathrm{~s}^{-1}$ according to ASTM-E8/E8 M-08 standard. The specimen size, sampling position, and specific fixture are shown in Fig. 1. The tensile specimens were cut from the $\mathrm{BM}$ and $\mathrm{PZ}$ along the $\mathrm{PD}$ and $\mathrm{TD}$, respectively (hereafter named as BM-PD, BM-TD, FSP-PD, and FSPTD specimens) (Fig. 1a). The PZ was completely located in the parallel section of tensile specimen with a dimension of $2 \mathrm{~mm} \times 2 \mathrm{~mm} \times 1 \mathrm{~mm}$. Each testing was repeated at least three times to guarantee the accuracy of data.

\section{Results and Discussion}

Figure 2a shows the cross-sectional macroscopic appearance of FSP pure Zr. A basin-shaped PZ can be obviously observed. The BM exhibited a coarse and heterogeneous 

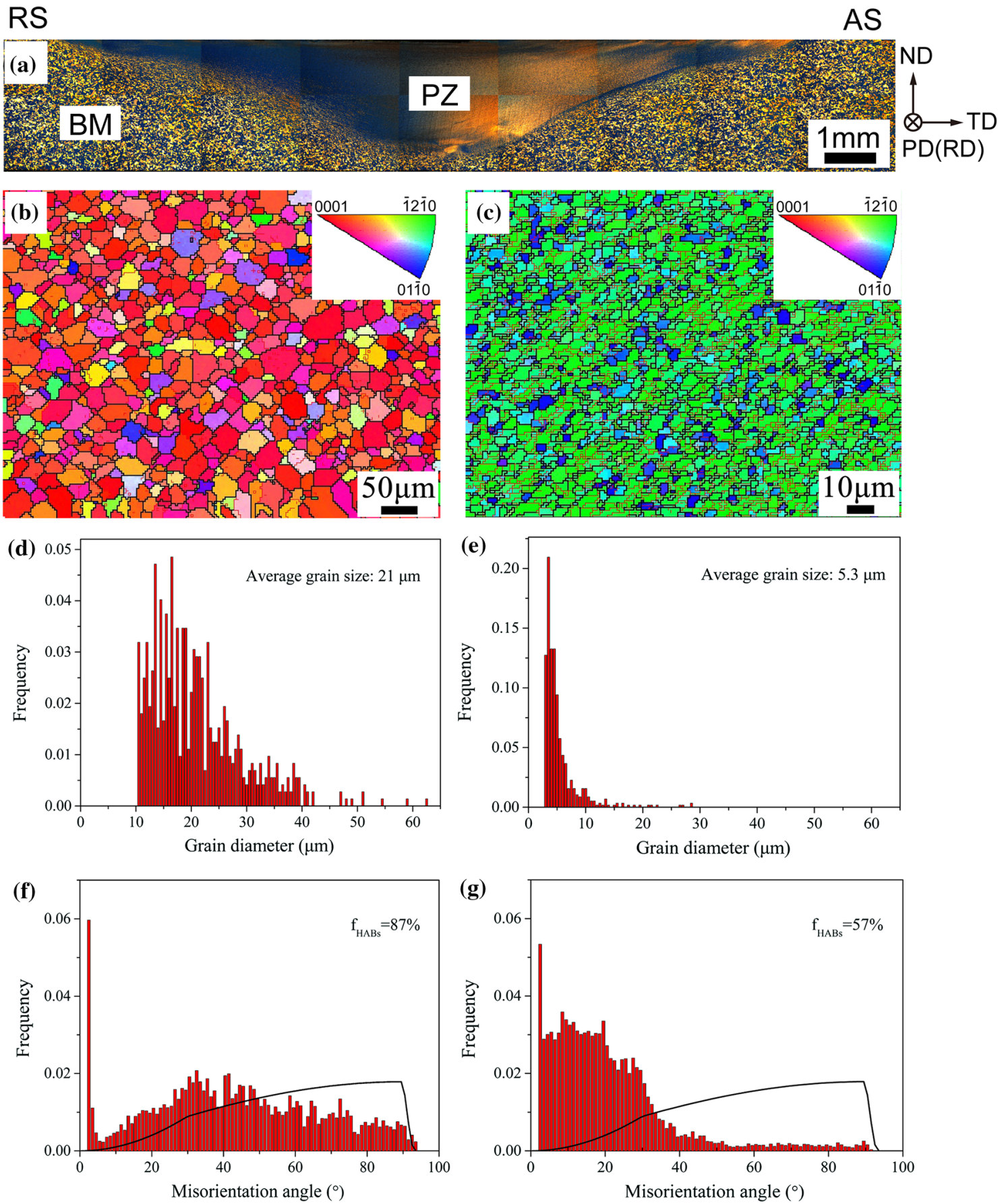

Fig. 2 a Cross-sectional macrostructure of FSP pure Zr, b, $\mathbf{c}$ IPFs, $\mathbf{d}, \mathbf{e}$ grain size distributions, $\mathbf{f}, \mathbf{g}$ misorientation angle distributions in $\mathbf{d}, \mathbf{f}$ BM, e, $\mathbf{g}$ PZ, respectively

microstructure with an average grain size of $\sim 21 \mu \mathrm{m}$ (Fig. 2b). By contrast, the PZ showed fine and equiaxed grains with an average grain size of $\sim 5.3 \mu \mathrm{m}$ due to the occurrence of dynamic recrystallization (DRX) induced by the combined effect of frictional heating and dramatic plastic deformation during FSP (Fig. 2c). Additionally, both BM and $\mathrm{PZ}$ exhibited a unimodal grain size distribution, and the former showed a larger dispersion than the latter (Fig. 2d, e). It should be noted that HAB proportion of the BM and PZ was $87 \%$ and $57 \%$, respectively (Fig. 2f, g). The decrease in HABs in the PZ indicated the developed substructure via continuous DRX (CDRX) in the grains interior. In a previous study, Li et al. [23] also indicated that CDRX played a major role in the microstructure evolution in the $\mathrm{PZ}$ during 
FSW Zr-Ti alloy. Sato et al. [19] reported that, in addition to CDRX, discontinuous DRX (DDRX) was a possible mechanism for FSW Zircaloy-4 alloy. Nevertheless, Xu et al. [24] showed that grain subdivision and DDRX contributed most to the grain refinement during FSW $\mathrm{Zr}-4$ alloy. A similar mechanism had been demonstrated in FSP pure Ti [25]. However, as to whether, DDRX mechanism occurred in the $\mathrm{PZ}$ requires further verification in this study.

Figure 3 shows the texture of the BM and PZ by means of $\{0002\},\{10 \overline{1} 0\}$, and $\{10 \overline{1} 2\}$ PFs. The BM showed a weak rolled texture, i.e., $\{0002\}$ planes slightly rotated away from ND toward TD and $\langle 10 \overline{1} 0\rangle$ directions parallel to RD. Following FSP, texture intensity of the PZ significantly increased, as well as texture component changed to an orientation of $\sim 45^{\circ}$ tilt angle between $c$-axis and PD. The modification of texture was mainly attributed to shear deformation induced by the synergistic effect of shoulder and stir pin [26-29]. The similar texture component appeared in the PZ during FSW Zr-4 alloy [24]. Sato et al. [19] found several ideal simple shear textural components, such as $\mathrm{P}$ and B-fiber texture as well as $\{\overline{1} 100\}\langle 11 \overline{2} 0\rangle$ texture in the PZ of FSW Zr-4 alloy joint, which showed that material flow during FSW arose mainly from the prismatic and the basal slips. Similarly, Li et al. [23] demonstrated that the PZ exhibited $\{\overline{11} 0\}\langle\overline{1} 1 \overline{2}\rangle$ shear texture, and the predominant deformation mode was shear deformation during FSW Zr-Ti alloy.

Figure 4 shows cross-sectional microhardness distribution of FSP pure Zr. The average microhardness of the PZ was $198 \mathrm{HV}, 1.6$ times higher than that of the BM.
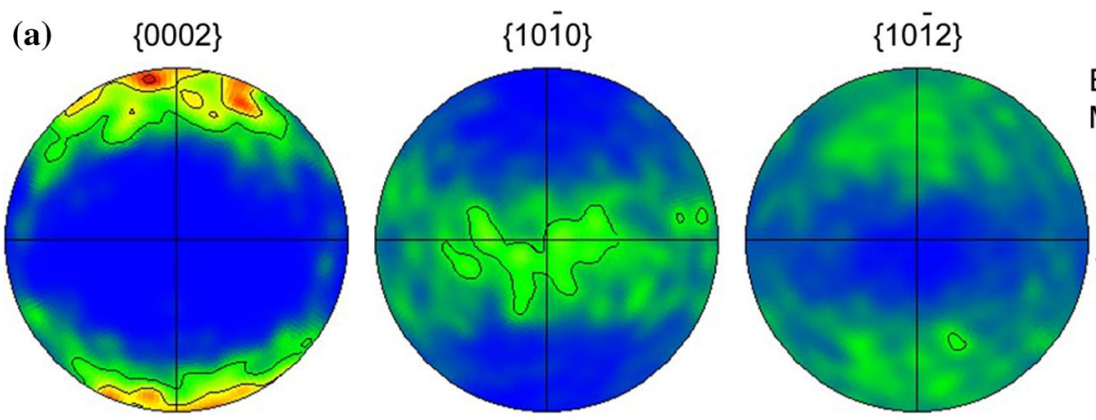

Exp. densities[mud]: Min=0, Max $=6.31$
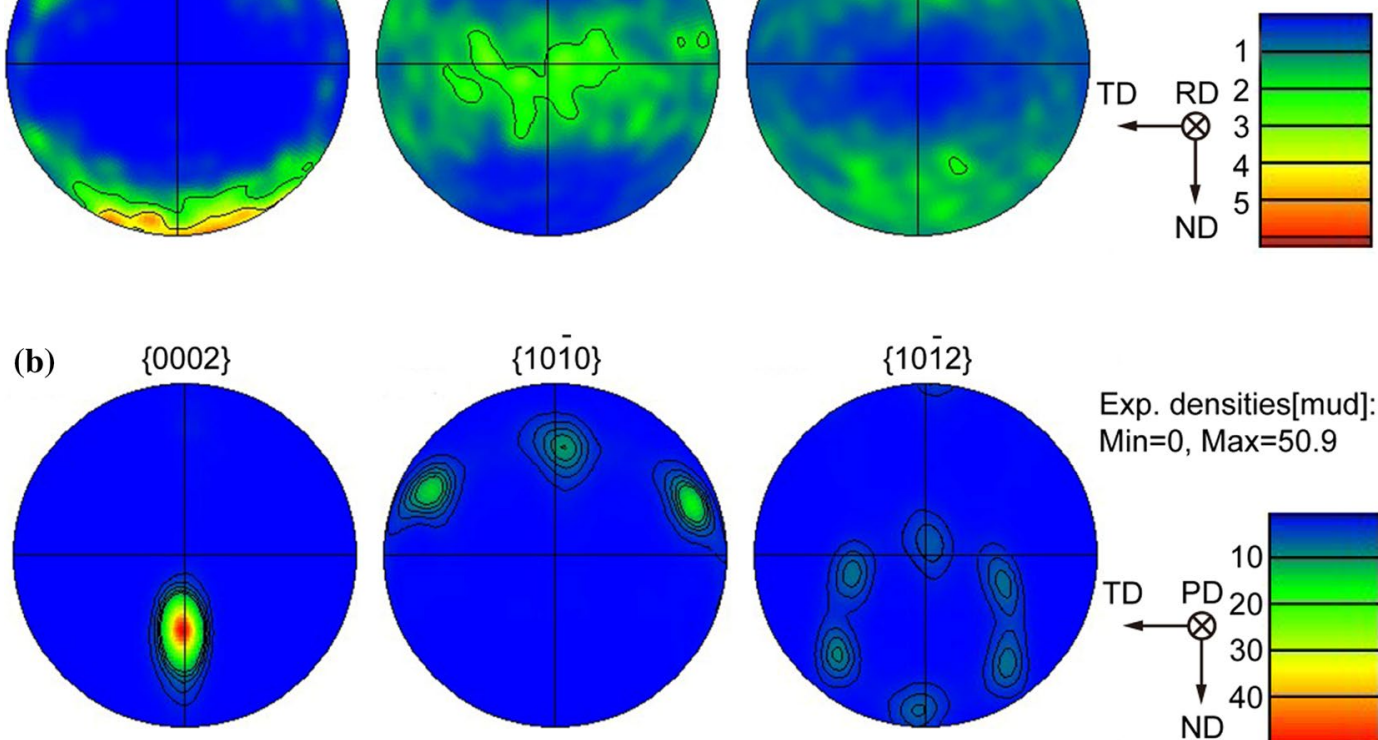

Exp. densities[mud]: Min=0, Max=50.9

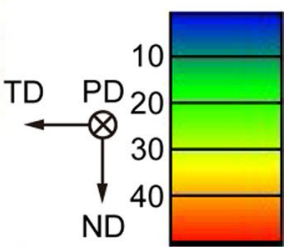

Fig. 3 PFs in a BM, b PZ

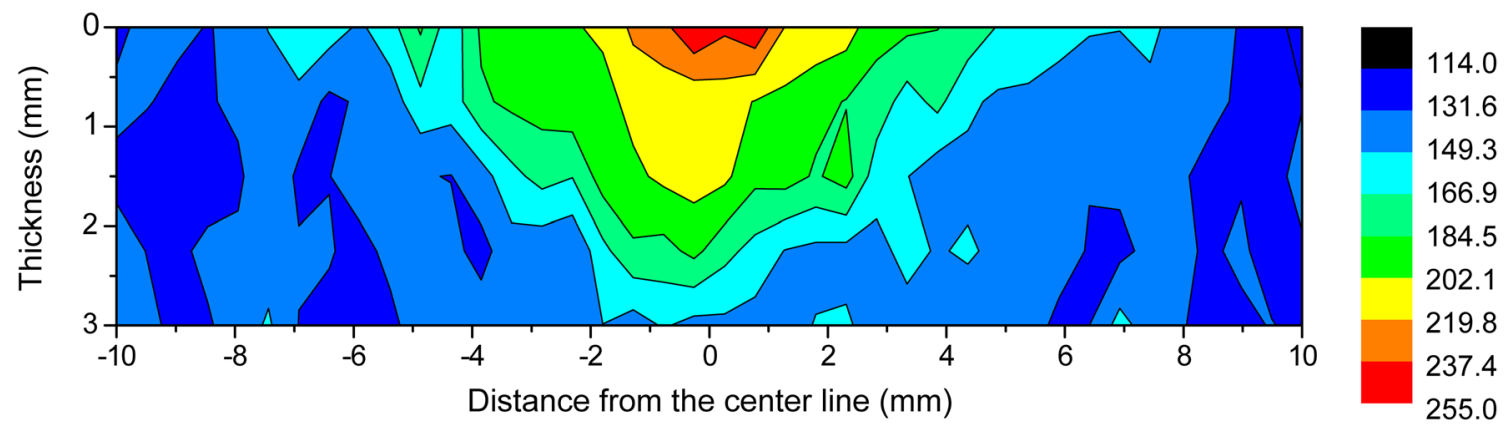

Fig. 4 Cross-sectional microhardness distribution of FSP pure $\mathrm{Zr}$ 


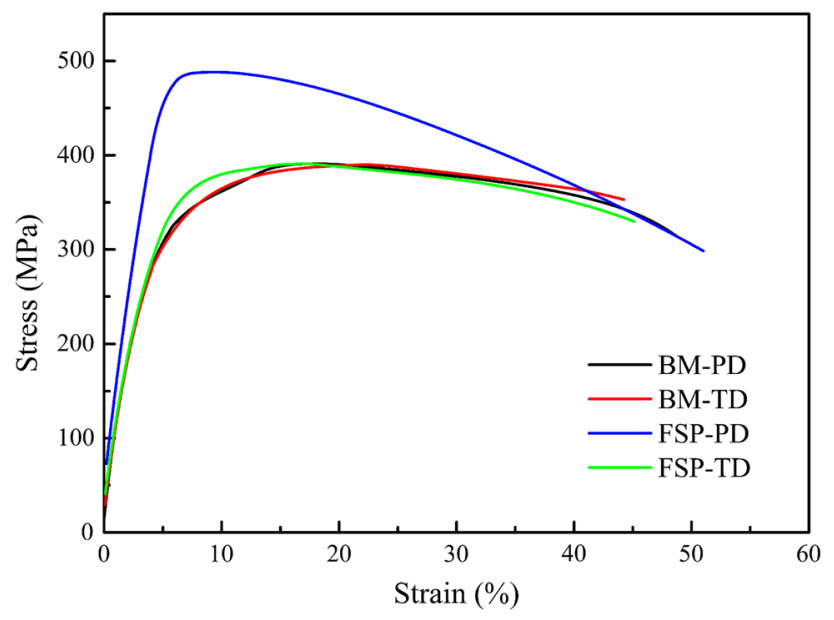

Fig. 5 Engineering stress-strain curves of BM-PD, BM-TD, FSP-PD and FSP-TD specimens

Table 1 Tensile property of BM and FSP specimens

\begin{tabular}{lllll}
\hline Specimens & $\sigma_{\mathrm{s}}(\mathrm{MPa})$ & $\sigma_{\mathrm{b}}(\mathrm{MPa})$ & $\varepsilon_{\mathrm{u}}(\%)$ & $\varepsilon_{\mathrm{t}}(\%)$ \\
\hline BM-PD specimen & $135 \pm 5$ & $391 \pm 3$ & $18 \pm 2$ & $48 \pm 1$ \\
BM-TD specimen & $137 \pm 6$ & $390 \pm 5$ & $18 \pm 4$ & $44 \pm 3$ \\
FSP-PD specimen & $248 \pm 3$ & $483 \pm 5$ & $10 \pm 1$ & $51 \pm 2$ \\
FSP-TD specimen & $136 \pm 4$ & $391 \pm 7$ & $16 \pm 2$ & $45 \pm 3$ \\
\hline
\end{tabular}

Meanwhile, the microhardness exhibited gradient distribution, i.e., microhardness value gradually decreased from the top surface to the bottom surface and from the center to the edges. This was mainly resulted from inhomogeneous plastic strain and heat input during FSP.

Figure 5 shows engineering stress-strain curves of BM-PD, BM-TD, FSP-PD, and FSP-TD specimens. The yield strength $\left(\sigma_{\mathrm{s}}\right)$, ultimate tensile strength $\left(\sigma_{\mathrm{b}}\right)$, uniform elongation $\left(\varepsilon_{\mathrm{u}}\right)$, and total elongation $\left(\varepsilon_{\mathrm{t}}\right)$ of the specimens were summarized in Table 1. For FSP specimen tested along the PD, the yield strength and ultimate tensile strength increased by $~ 84 \%$ and $24 \%$, respectively, as compared with the BM specimen tested along the same direction, and total elongation slightly increased by $\sim 6 \%$, while uniform elongation was decreased by $\sim 44 \%$. Meanwhile, for FSP specimen tested along the TD, the strengths $\left(\sigma_{\mathrm{s}}, \sigma_{\mathrm{b}}\right)$, and elongations $\left(\varepsilon_{\mathrm{u}}, \varepsilon_{\mathrm{t}}\right)$ were almost same with the corresponding BM specimen. Furthermore, it should be noted that the anisotropy of the FSP specimen in tensile property was more obvious than that of the BM specimen owing to stronger texture feature (Fig. 3).

For hcp pure $\mathrm{Zr}$, the axial ratio $c / a$ was 1.593 , which was lower than that of the ideal value of 1.633. Accordingly, lattice resistance for prismatic planes was lower than that for basal or pyramidal planes at room temperature, thus, dislocation slip preferred to occur on prismatic planes [30]. In other words, prismatic slip was easily activated during tensile deformation at room temperature.

Figure 6 shows the Schmid factors (SFs) distribution of prismatic slip systems of BM and FSP specimens tested along the $\mathrm{PD}$ and the TD, respectively. It can be clearly seen that the FSP-PD specimen had much lower SF than the FSPTD specimen. As a result, the FSP-PD specimen had much higher strength than the FSP-TD specimen even though both specimens possessed the same microstructure. Besides the external tensile direction, intrinsic texture also has a significant effect on the tensile property. This can be clearly demonstrated by comparing the tensile properties between BM specimen and FSP specimen tested along the same tensile direction, because both specimens had the different intrinsic textures (Fig. 3). The FSP-PD specimen had much higher strength compared with the BM-PD specimen. This is due to that FSP-PD specimen possessed finer grains (Fig. 2b, c), higher dislocation densities (Fig. 2f, g) and texture hardening effect (Fig. 6). On the contrary, compared with the BM-TD specimen, the FSP-TD specimen exhibited almost the same tensile strength. This was mainly because that synergetic effect of texture softening, fine-grained strengthening and dislocation strengthening maintained a balance, and ultimately resulted in almost the same tensile strength.

In general, plastic deformation behavior of polycrystalline materials is strongly dependent on the grain size and its distribution, texture, and twinning. Therefore, besides the grain size and texture effects as discussed above, other factors should have great influence on the mechanical properties of pure $\mathrm{Zr}$.

As far as the twins are concerned, several studies have demonstrated that twins can act as effective barriers to dislocation slip or create easy glide regions. Generally, twins are easily activated during plastic deformation at low temperature and/or high strain rate. Accordingly, in this study, the twins were not easily formed in both BM and FSP specimens due to a low strain rate of $1 \times 10^{-3} \mathrm{~s}^{-1}$ during tensile deformation. For the FSP specimens, there were two additional reasons responsible for the absence of twins. On the one hand, the twins are prone to form in coarse grains, while FSP resulted in a significant grain refinement (Fig. 2c, e), which was not beneficial to the formation of twins due to high activation energy. On the other hand, the texture of FSP specimens (Fig. 3) was not favorable to twinning, which normally requires $c$-axis parallel to the loading axis during tensile or compressive deformation [31].

Grain size distribution also has a significant effect on plastic deformation [32]. Structural materials with bi/multimodal structures have been demonstrated to possess good mechanical properties [33, 34]. For the structural materials with a bimodal distribution of grain size, fine grains resulted in a high strength, while coarse grains caused a high 

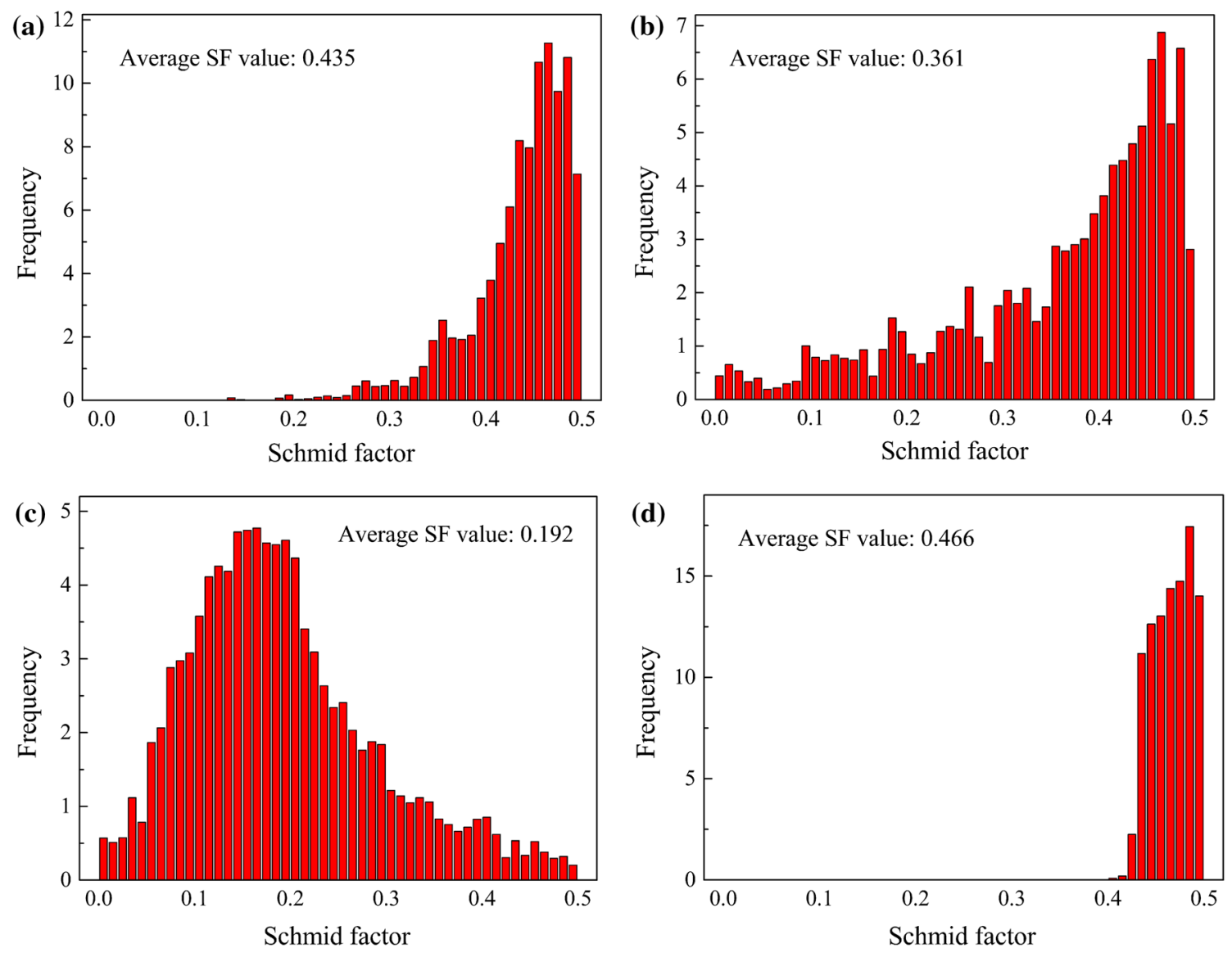

Fig. 6 SFs distributions of prismatic slip $\{10 \overline{1} 0\}\langle 1 \overline{2} 10\rangle$ of different specimens: a BM-PD, b BM-TD, c FSP-PD, d FSP-TD specimens

work-hardening rate and elongation while keeping a constant average grain size [35, 36]. In this study, both FSP and BM specimens showed unimodal distributions of grain size, and the latter showed a larger dispersion than the former (Fig. 2d, e). Therefore, grain size distribution contributed less to the ductility and strain hardening of FSP specimen than those of BM specimen.

The strain hardenability of materials affects their plasticity. It is well known that the strain hardening occurs with interactions of dislocations with grain boundaries, twin boundaries and the second phases. For pure $\mathrm{Zr}$, the effect of second phases on the strain hardening can be negligible. Moreover, twins were not available in FSP pure $\mathrm{Zr}$ due to fine grains (Fig. 2c, e). Therefore, the interaction of dislocations with grain boundaries actually affected the strain hardenability of FSP pure Zr. In general, grain refinement can decrease the dislocation free path, and thus results in a low plasticity. For example, the grain size of pure $\mathrm{Zr}$ was refined to $110 \mathrm{~nm}$ via $\mathrm{ARB}$, and consequently, the uniform elongation drastically reduced to 5\% [37]. The low uniform elongation of $0.6 \%$ was also reported in UFG pure $\mathrm{Zr}$ fabricated via HPT [2]. In contrast, FSP FG Zr kept a good uniform elongation $(10 \%$ and $16 \%)$ in this work. This is attributed to that moderate grain refinement resulted in reasonable strain hardening capability for FSP FG Zr.

Figure 7 shows a comparison of tensile properties of FG and UFG pure Zr fabricated by FSP and other SPD techniques [4, 37-42]. It can be clearly seen that there is an inverted relationship between the strength and elongation (shade area as shown in Fig. 7). The most striking result is that FSP-PD specimen fabricated via FSP in this study is away from the shade area, indicating a simultaneous improvement of ultimate tensile strength and uniform elongation as compared with FG and UFG $\mathrm{Zr}$ fabricated via other SPD techniques, such as ARB, HTP, and cryogenic rolling. In conclusion, FSP is an effective method of improving strength of pure $\mathrm{Zr}$, while keeping a good ductility.

\section{Conclusions}

1. FSP resulted in the grain refinement of pure $\mathrm{Zr}$ from $\sim 21 \mu \mathrm{m}$ to $\sim 5.3 \mu \mathrm{m}$ due to the occurrence of CDRX. HAB proportion decreased from $87 \%$ to $57 \%$. Meanwhile, FSP not only resulted in the increase in tex- 


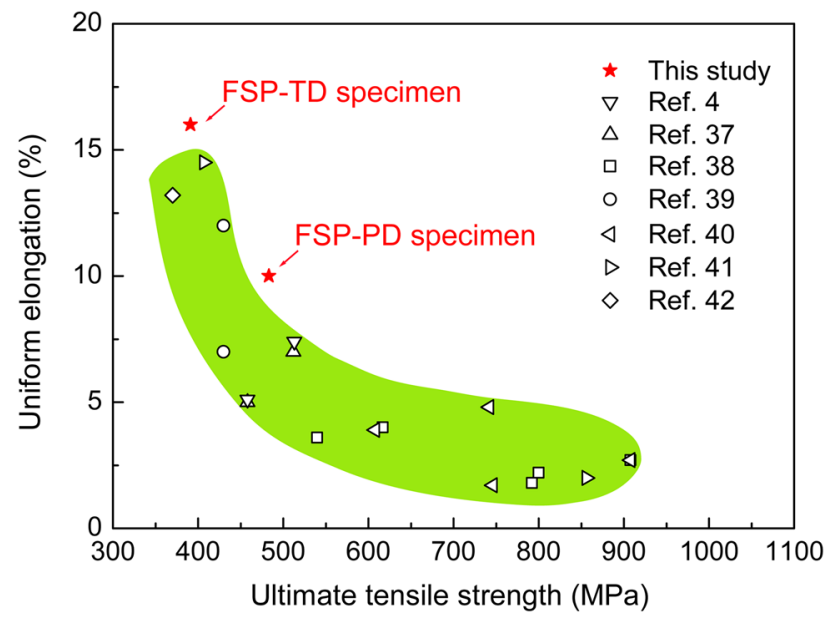

Fig. 7 Representative tensile properties of FG and UFG pure $\mathrm{Zr}$ fabricated by SPD techniques. Hollow symbols are reported data in the literature [4, 37-42]. Solid symbols are experimental data in this study

ture intensity, but also led to the variation of texture component with $c$-axis being tilted $\sim 45^{\circ}$ toward PD.

2. The average microhardness of $\mathrm{PZ}$ was $\sim 198 \mathrm{HV}, 1.6$ times higher than that of the BM. Furthermore, the microhardness exhibited gradient distribution.

3. FG pure $\mathrm{Zr}$ showed obvious anisotropy in tensile properties. FSP-PD specimen had much higher strength than FSP-TD specimen. High yield strength (248 MPa) and ultimate tensile strength (483 MPa), as well as good uniform elongation (10\%) were obtained for FSP-PD specimen.

Acknowledgements The authors gratefully acknowledge the sponsorship from the National Natural Science Foundation of China (Nos. U1760201, 51404180, and 51574192), the National Key Research and Development Program of China (No. Z20180407), the Key Industrial Research Program of Shaanxi Province, China (No. 2017ZDXMGY-037), and the Youth Innovation Team of Shaanxi Universities (No. 2019-2022)

\section{References}

[1] F. Djavanroodi, A.A. Zolfaghari, M. Ebrahimi, K. Nikbin, Acta Metall. Sin. (Engl. Lett.) 27, 95 (2014)

[2] K. Edalati, Z. Horita, S. Yagi, E. Matsubara, Mater. Sci. Eng. A 523, 277 (2009)

[3] H. Asgharzadeh, H. Faraghi, H.S. Kim, Acta Metall. Sin. (Engl. Lett.) 30, 973 (2015)

[4] L. Jiang, M.T. Pérez-Prado, P.A. Gruber, E. Arzt, O.A. Ruano, M.E. Kassner, Acta Mater. 56, 1228 (2008)

[5] R.S. Mishra, Z.Y. Ma, Mater. Sci. Eng. R 50, 1 (2005)

[6] A.H. Ammouri, G. Kridli, G. Ayoubcd, R.F. Hamade, J. Mater. Process. Technol. 222, 301 (2015)

[7] I. Charit, R.S. Mishra, J. Mater. Sci. Technol. 34, 214 (2018)

[8] W. Wang, K.S. Wang, Q. Guo, N. Wu, Rare Met. Mater. Eng. 41, $1522(2012)$
[9] W. Wang, K. Qiao, J.L. Wu, T.Q. Li, J. Cai, K.S. Wang, Sci. Technol. Weld. Join. 22, 110 (2017)

[10] W. Wang, R.Q. Xu, Y.X. Hao, Q. Wang, L.L. Yu, Q.Y. Che, J. Cai, K.S. Wang, Z.Y. Ma, J. Mater. Sci. Technol. 34, 148 (2018)

[11] K.S. Wang, J.L. Wu, W. Wang, L.H. Zhou, Z.X. Lin, L. Kong, J. Cent, J. Cent. South Univ. 19, 2081 (2012)

[12] C.Y. Liu, B. Qu, P. Xue, Z.Y. Ma, K. Luo, M.Z. Ma, R.P. Liu, J. Mater. Sci. Technol. 34, 112 (2018)

[13] J.A. Del Valle, P. Rey, D. Gesto, D. Verdera, J.A. Jiménez, O.A. Ruano, Mater. Sci. Eng. A 628, 198 (2015)

[14] Y.Q. Mao, L.M. Ke, Y.H. Chen, F.C. Liu, L. Xing, J. Mater. Sci. Technol. 34, 228 (2018)

[15] Z.N. Yang, Y.Y. Xiao, F.C. Zhang, Z.G. Yan, Mater. Sci. Eng. A 556, $728(2012)$

[16] A. Fattah-alhosseini, M. Vakili-Azghandi, M. Sheikhi, M.K. Keshavarz, J. Alloys Compd. 704, 499 (2017)

[17] G.M. Xie, Z.Y. Ma, L. Geng, Scr. Mater. 57, 73 (2007)

[18] P. Xue, B.B. Wang, F.F. Chen, W.G. Wang, B.L. Xiao, Z.Y. Ma, Mater. Charact. 121, 187 (2016)

[19] Y.S. Sato, Y. Nagahama, S. Mironov, H. Kokawa, S.H.C. Park, S. Hirano, Scr. Mater. 67, 241 (2012)

[20] B.S. Lee, M.H. Kim, Mater. Sci. Eng. A 416, 150 (2006)

[21] B.S. Lee, M.H. Kim, Mater. Sci. Eng. A 423, 180 (2006)

[22] B.S. Lee, M.H. Kim, S.K. Hwang, S.I. Kwun, S.W. Chae, Mater. Sci. Eng. A 449, 1087 (2007)

[23] Y.J. Li, R.D. Fu, D.X. Du, L.J. Jing, D.L. Sang, X.Y. Zhang, Sci. Technol. Weld. Join. 19, 588 (2014)

[24] N. Xu, Q.N. Song, Y.F. Bao, Y.F. Jiang, J. Shen, Mater. Sci. Technol. 34, 20 (2018)

[25] Y. Zhang, Y.S. Sato, H. Kokawa, S.H.C. Park, S. Hirano, Sci. Technol. Weld. Join. 15, 500 (2010)

[26] L.Y. Huang, K.S. Wang, W. Wang, J. Yuan, K. Qiao, T. Yang, P. Peng, T.Q. Li, Eng. Fail. Anal. 92, 392 (2018)

[27] Q.Y. Che, K.S. Wang, W. Wang, L.Y. Huang, T.Q. Li, X.P. Xi, P. Peng, K. Qiao, Rare Met. (2019). https://doi.org/10.1007/s1259 8-019-01217-2

[28] F.C. Liu, Y. Hovanski, M.P. Miles, C.D. Sorensen, T.W. Nelson, J. Mater. Sci. Technol. 34, 39 (2018)

[29] S. Mironov, Y.S. Sato, H. Kokawa, J. Mater. Sci. Technol. 34, 58 (2018)

[30] C. Yuan, Y.P. Wang, D.L. Sang, Y.J. Li, L. Jing, R.D. Fu, X.Y. Zhang, J. Alloys Compd. 619, 513 (2015)

[31] R.J. McCabe, G. Proust, E.K. Cerreta, A. Misra, Int. J. Plast 25, 454 (2009)

[32] B. Zhu, R.J. Asaro, P. Krysl, K. Zhang, J.R. Weertman, Acta Mater. 54, 3307 (2006)

[33] Y.M. Wang, M.W. Chen, F.H. Zhou, E. Ma, Nature 419, 912 (2002)

[34] Y. Zhao, T. Topping, J.F. Bingert, J.J. Thornton, A.M. Dangelewicz, Y. Li, W. Liu, Y. Zhu, Y. Zhou, E.J. Lavernia, Adv. Mater. 20, 3028 (2008)

[35] D.M. Sekban, S.M. Akterer, O. Saray, Z.Y. Ma, G. Purcek, J. Mater. Sci. Technol. 34, 237 (2018)

[36] Y.G. Liu, J.Q. Zhou, X. Ling, Mater. Sci. Eng. A 527, 1719 (2010)

[37] L. Jiang, O.A. Ruano, M.E. Kassner, M.T. Pérez-Prado, JOM 59, 42 (2007)

[38] D.F. Guo, M. Li, Y.D. Shi, Z.B. Zhang, H.T. Zhang, X.M. Liu, X.Y. Zhang, Mater. Lett. 66, 305 (2012)

[39] S. Care, T. Bretheau, J. Phys. IV 3, 533 (1993)

[40] D. Guo, M. Li, Y. Shi, Z. Zhang, H. Zhang, X. Liu, B. Wei, X. Zhang, Mater. Des. 34, 275 (2012)

[41] C. Yuan, R.D. Fu, D.L. Sang, Y.Q. Yao, X.Y. Zhang, Mater. Lett. 107, 134 (2013)

[42] D.F. Guo, Z.B. Zhang, G.S. Zhang, M. Li, Y.D. Shi, T.Y. Ma, X.Y. Zhang, Mater. Sci. Eng. A 591, 167 (2014) 